\title{
ANTECEDENTES DA SATISFAÇÃO NO SETOR IMOBILIARIO
}

\section{RESUMO}

Este artigo examina a confiança tanto no vendedor como na empresa, a qualidade e o valor percebidos do produto pelos clientes como antecedentes da satisfação em compras de al to valor, como a compra de um imóvel residencial na planta. Foi desenvolvida e testada uma proposição teórica, com dados do mercado imobiliário brasileiro, usando-se modelagem de equações estruturais. Os resultados indicam que a satisfação com o corretor de imóveis influencia a confiança para com ele, mas experiências anteriores e características dos corretores em geral não têm impacto sobre essa variável. Detectou-se, ainda, que o valor percebido do produto e a confiança no corretor e na construtora têm influência sobre a satisfação com a compra, mas não sobre a qualidade percebida do produto. São discutidas as implicações dos resultados para a pesquisa e a gestão de marketing, mais especificamente no campo do marketing imobiliário.

\section{Alda Rosana Duarte de Almeida \\ FEA-USP}

\section{Delane Botelho}

FGV-EBAPE

\footnotetext{
ABSTRACTThis paper examines the trust that clients have, both in the salesman and in the company, and the product's perceived quality and value as being the antecedents of satisfaction with high value purchases, such as the purchase of a residential property when only the plans exist. A theoretical proposition was developed and tested, using data from the Brazilian real estate market and structural equation modeling. The results indicate that satisfaction with the real estate broker has an influence on the trust placed in her/him, but that previous experiences and the characteristics of brokers in general have no impact on this variable. It was al so detected that the product's perceived value and trust in the broker and the homebuilder have an influence on the satisfaction with the purchase, but not on the perceived value of the product. The implications of the results for research and marketing management, more specifically in the field of real estate marketing, are discussed.
}

PALAVRAS-CHAVE Confiança, satisfação, valor, qualidade, compras de valor.

KEYMORDSTrust, satisfaction, value, quality, high value purchases. 


\section{INTRODUÇÃO}

A presente pesquisa se baseia na proposição e teste de um modelo conceitual com foco não na freqüência do consumo, mas na primeira (ou primeiras) compra(s), tratando-se de compra de imóvel residencial na planta ou em construção.

Entre os construtos mercadológicos mais pesquisados sobre relacionamentos das organizações com seus clientes, individuais ou organizacionais, incluem-se confiança, satisfação, leal dade e qual idade percebida. Estudos no exterior (DONEY, CANN ON, 1997; OLIVER, 1999; CHUNG e outros, 2008) e no Brasil (BREI, ROSSI, 2002; SANTOS, FERN ANDES, 2008) têm comprovado essa tendência.

Diversos autores (GARBARINO, JOHNSON, 1999; FLAVIÁN e outros, 2006; BOTELHO, 2007) têm se dedicado a avaliar as relações entre confiança e satisfação, tanto nas organizações como na sua força de vendas e produtos, com o objetivo demanter eprospectar clientes. Conquistar a confiança do cliente passou a ser tão ou mais importante do que obter a satisfação com o produto ou com a compra.

Este artigo examina a confiança tanto no vendedor como na empresa, o valor e a qualidade percebidos do produto pelos clientes como antecedentes da satisfação na compra de um imóvel, ou seja, uma compra de alto envolvimento. Fatores importantes que estimularam este estudo foram a carência de pesquisas relacionando essas variáveis no marketing imobiliário, a carência de estudos sobre confiança e satisfação em compras com al to envolvimento financeiro e emocional do cliente, e a necessidade de se examinar a importância do produto e dos vendedores no mercado imobiliário. Em pesquisas nos principais periódicos e congressos acadêmicos internacionais e nacionais da área de marketing, nos últimos cinco anos, nenhum trabal ho empírico relacionando satisfação a confiança na compra de um produto intangível dessa natureza (imóvel na planta, que se trata da promessa de entrega de um bem tangível com agregação de serviços) foi encontrado. Conseqüentemente, o panorama apresentado estimula a analisar e estudar os relacionamentos, atitudes, percepções e constatações de clientes na compra de um imóvel residencial na planta. N esse contexto, buscase investigar o seguinte problema: a confiança, o valor e a qualidade percebidos pelos clientes são ou não fatores antecedentes da satisfação com a compra de um imóvel residencial na planta?

Esta introdução apresentou o tema e o objetivo da pesquisa. A segunda seção contém a fundamentação teórica do modelo proposto. A terceira seção apresenta o método da pesquisa, abrangendo a operacional ização das variáveis, os procedimentos de coleta e a anál ise dos dados. A quarta seção mostra os resultados e sua anál ise. 0 artigo é finalizado com as principais conclusões da pesquisa, inclusive suas limitações, implicações gerenciais e para a pesquisa em marketing, e sugestões para estudos futuros.

\section{FUNDAMENTAÇÃO TEÓRICA}

U ma compra de valor, ou de al to envolvimento, é caracterizada por alto planejamento, envolvimento das pessoas interessadas, principal mente na decisão de compra, emprego de maior tempo na pesquisa do produto, preço e marcas que se deseja adquirir (BRETZKE, 2003, p. 82). Ademais, na compra de uma residência, além do preço a ser pago pelo imóvel, há outros fatores (como comprometimento da renda, tipo de financiamento, tipo de construção, economias necessárias para a aquisição do produto, localização do imóvel e qualidade da construção) que associam custos não monetários à compra, como os custos psicológicos, gerando uma percepção de risco maior do que aquela associada ao valor monetário do produto.

Este estudo se limita à análise de imóveis na planta ou em construção, ou seja, ao produto ainda intangível, não abordando o setor de imóveis prontos. Em conseqüência do foco do estudo, a literatura de marketing de serviços se mostrou importante para este trabal ho: a tangibilidade do produto final a partir do imóvel na planta ou em construção pode ocorrer muito tempo depois de efetivada a compra. A tangibilidade do produto pode melhorar a confiança do cliente potencial na sua avaliação, reduzindo, assim, a influência das comunicações boca-a-boca, que dificultam a avaliação do consumidor, como é o caso da compra de imóveis na planta (BERRY, PARASURAMAN, 1995).

A seguir, são apresentadas as definições teóricas e as hipóteses desta pesquisa.

\section{Confiança}

A confiança tem sido estudada por muitos autores como um construto importante em diferentes tipos de relacionamentos com clientes, gerando amplo número de definições (SANTOS, 2001; DONEY, CAN NON , 1997; BIGNE, BLESA, 2003; SANTOS, FERNAN DES, 2008). Para Santos (2001, p. 36), a confiança é definida como "um estado psicológico compreendendo a intenção para aceitar vulnerabilidade baseada em positivas expectativas sobre as intenções e comportamentos do outro". A autora concluiu que a confiança impacta diretamente a lealdade, sendo fundamental para o desenvolvimento de fortes e longos relacionamentos entre consumidores e organizações. 
Para Santos e Rossi (2002), a confiança do consumidor, no contexto de serviços, é um construto bifacetado - confiança nos funcionários e confiança nas práticas gerenciais. Em contraponto, o presente estudo enfoca apenas a confiança na pessoa que tem contato direto com o cliente na venda do imóvel, o corretor de imóveis, não analisando a influência das práticas gerenciais das empresas envol vidas na venda. Santos e Rossi (2002) também citam que, em um relacionamento contínuo, a confiança é associada a qualidades como consistência, competência, honestidade, integridade, responsabilidade e benevolência, etem papel central na promoção da cooperação entre as partes. Para Garbarino e Johnson (1999), o benefício psicológico da confiança é mais importante do que o tratamento especial dispensado ou os benefícios sociais no relacionamento de consumidores com empresas de serviços.

Em compras de al to envolvimento do cliente, o período de tempo anterior à compra do produto pode proporcionar a construção de um relacionamento pré-compra (BRETZKE, 2003). No presente estudo, a confiança é medida tanto no corretor de imóveis quanto na construtora, como antecedentes da satisfação com a compra do imóvel. As duas definições operacionais de confiança são apresentadas a seguir.

\section{Confiança no corretor}

Quando o cliente potencial vai até o stand de vendas da construtora, provavel mente já reconheceu a necessidade e está no estágio seguinte do processo de compra. N esse momento, o corretor passa a ter um papel importante, de prestar informações sobre as características da obra, tais como local ização, planta, qual idade, opções de lazer, preço, prazo de entrega e condições de financiamento (MUTRAN, 2003). Cinqüenta por cento das pessoas não decidem a compra do apartamento durantea visita ao stand, mesmo tendo todas as informações necessárias. Com isso, o relacionamento entre o corretor eo cliente podese intensificar com passar do tempo (MUTRAN, 2003).

A confiança no vendedor é uma dimensão da qualidade do relacionamento e se define como a crença na honestidade e integridade que 0 cliente tem no vendedor (CROSBY e outros, 1990). Doney e Cannon (1997) definiram confiança como a percepção da credibilidade e benevolência do cliente no vendedor, não relacionada à escolha da compra. Tal confiança apresenta três características: (1) competência, que significa que o cliente acredita que 0 vendedor tem a habilidade para fazer o que precisa ser feito; (2) benevolência, que é a amplitude do que 0 vendedor quer fazer de melhor pelo cliente; e (3) integridade, que significa que se acredita que 0 vende- dor fale a verdade, aja eticamente e cumpra as promessas (SUH, HAN, 2003).

Em geral, as definições de confiança demonstram que ela está ligada à condiç̧ão de qualidade, em vez de aspectos econômicos, como o preço do produto. Isso não invalida, porém, o fato de que a falta de confiança poderá inviabilizar a realização da negociação. Assim, neste artigo, a confiança no corretor é enten dida como o benefício psicológico construído a partir da integridade, credibilidade, benevolência, dignidade e sinceridade percebidas pelo cliente (DONEY, CAN N ON, 1997; SUH, HAN, 2003; GARBARIN O, JOHNSON, 1999).

\section{Confiança na construtora}

Uma marca de confiança no mercado, principalmente quando a compra gera an gústia nos compradores, reflete a imagem do produto ou da empresa. A imagem da marca, ou da empresa, é o conjunto de percepções e associações que o consumidor desenvolve com relação a um produto (BRETZKE, 2003). Essa imagem evidencia a credibilidade da empresa, ou do produto, no mercado.

A confiança existe quando uma parte, no caso o cliente, tem confiança na fidedignidade e integridade do parceiro envolvido na negociação, no caso, a empresa ( MORGAN e HUNT, 1994). Andaleeb (1996) definiu confiança na empresa como a disposição de uma parte em confiar no comportamento da outra que está envolvida na negociação, especialmentequando esse comportamento apresenta implicações nos resultados da parte que concedeu a confiança. A concessão da confiança pelo cliente é precedida pela crença nas ações da empresa em conduzir as negociações para resultados favoráveis a ambos.

No Brasil, especificamente, a confiança em construtoras é afetada por casos de falências, como a da empresa Encol S/A, que chegou a ser a maior empresa do setor de construção civil do país na década de 1980. Depois desse caso específico, os consumidores estão mais conscientes e atentos ao desempenho das construtoras (NEDER, 2004). A confiança na construtora é aqui definida como a percepção, pelo cliente, de integridade, honestidade e credibilidade na imagem da construtora.

\section{Satisfação}

A satisfação é um estado psicológico resultante de um processo avaliativo que compara uma referência interna preexistente aos efeitos reais da compra (Chauvel, 2000). Para essa autora, qualquer comportamento humano é uma "ação simbólica", que se situa no contexto de determinada relação. Não obstante, Crosby e Stephens (1987) conceituaram a satisfação do consumidor como tendo 
três faces: 1) satisfação com o contato pessoal; 2) com a prestação dos serviços; e 3) com a empresa. Aqui a satisfação é medida como precedente da confiança percebida pelo cliente em relação ao corretor de imóveis, e também como conseqüente de outras variáveis que influenciam a satisfação com a compra do imóvel. Tais definições específicas são apresentadas a seguir.

\section{Satisfação com o corretor}

A satisfação com o corretor de imóveis é, neste trabalho, um construto precedente da confiança no vendedor e, conseqüentemente, influencia relacionamentos, como nos estudos de Santos (2001), Santos e Fernandes (2004), e Ganesan (1994).

A satisfação do cliente com o vendedor reflete um estado emocional que ocorre em resposta à avaliação da interação de experiências (WESTBROOK, OLIVER, 1991). Ganesan (1994) desenvolveu um estudo em que analisa a satisfação como antecedente da confiança, observando que a satisfação do varejista com os resultados anteriores do relacionamento será crescente se perceber no fornecedor benevolência e credibilidade. Similarmente, Bigne e Blesa (2003), que focaram seu estudo no ponto de vista social, e não econômico, em relação à satisfação, argumentaram que a confiança e a satisfação estão correlacionadas e podem ser tanto antecedentes como conseqüentes, comprovando que a relação da satisfação com a confiança é positiva e significante.

Assim, a satisfação com o corretor de imóveis que efetivou a venda é aqui entendida como um estado emocional que ocorre em resposta à avaliação do relacionamento percebida pelo cliente.

\section{Satisfação com a compra do imóvel}

A satisfação com a compra do imóvel é analisada neste estudo como um construto conseqüente da confiança, tanto no vendedor (corretor) como no fornecedor (construtora), em acordo com os estudos de Mückenberger (2001) e Garbarino e Johnson (1999).

A decisão da compra de um imóvel é usual mente acompanhada de uma fase de insegurança e momentos de ansiedade. Mückenberger (2001) constatou que a ligação entre intenção e satisfação com a compra é intermediada pela confiança. A satisfação total é uma aval iação positiva, al ém de esperada, baseada na compra e na experiência de consumo (GARBARIN O, JOHNSON, 1999).

Oliver (1999) verificou quea satisfação com a compraé um estado temporal pós-uso, decorrente de uma situação de consumo única ou de experiências repetidas que refletem como um produto alcançou seu propósito. Existem várias defini ções de satisfação na literatura, mas a que tem recebido mais suporte é: "Satisfação é o julgamento da avaliação pós-escolha relativa a uma compra específica" (WEST BRO OK, OLIVER, 1991, p. 84, tradução nossa).

Em consonância com aos autores citados, a satisfação com a compra do imóvel é aqui definida como um estado psicológico construído a partir da confiança esperada, mantida e percebida durante a compra, e de acordo com as percepções dos clientes sobre a qualidade e o valor do produto.

\section{Características do corretor de imóveis}

0 desenvolvimento da confiança no vendedor também se dá pelas características do relacionamento (DONEY, CAN N ON, 1997). Na avaliação dos compradores, as características que lhes agradam em um vendedor são o fato de serem amigáveis, amáveis e agradáveis. Os vendedores reportaram que, se forem identificados como pessoas dignas de estima, ou mesmo como amigos, aumenta-se a chance de ganharem a confiança do cliente (SWAN e outros, 1985). A similaridade (entre o comprador e vendedor) e a habilidade de vendas do vendedor influenciam diretamente a eficiência das vendas, mas somente a habilidade influencia o relacionamento de venda a longo prazo por seu impacto na qualidade do relacionamento (CROSBY e outros, 1990). N este estudo, as características do corretor de imóveis são: (a) a percepção do cliente sobre o conhecimento do produto pelo corretor, (b) a similaridade entre cliente e corretor, e (c) a reputação e a amabilidade presentes no relacionamento entre cliente e corretor.

\section{Experiências anteriores e relacionamentos com corretores de imóveis em geral}

A confiança pode ser afetada porque os consumidores observam o comportamento do vendedor em várias situações, como compras anteriores, contatos informais de pesquisa ou mesmo pela avaliação de amigos e da mídia (DONEY, CAN NON, 1997). A freqüência com que vendedores e clientes se comunicam nos negócios ou por razões sociais tem sido determinante para a manutenção de relacionamentos com confiança (CROSBY e outros, 1990). Assim, experiências anteriores com corretores de imóveis são em geral aqui entendidas como a variedade de situações vivenciadas no passado pelos clientes, que perceberam a capacidade, a disposição e habilidade dos corretores com quem tiveram relacionamento.

\section{Valor percebido do produto}

Sob o ponto de vista do cliente, o preço expressa aquilo que ele está disposto a pagar para obter o produto 
(ROCHA, CHRISTENSEN, 1987). Porém, valor percebido é a "avaliação sumária de um produto pelo cliente, levando em consideração os benefícios e o preço, sendo que 0 valor total percebido é igual a benefícios percebidos mais o preço percebido" (VALLE, 2003, p. 110). Sirdeshmukh e outros (2002) definiram valor percebido como a percepção do benefício do cliente menos os custos das relações correntes com um serviço provido. 0 conceito mais utilizado de valor percebido na literatura de marketing é o de Zeithaml (1988), adotado por Brei e Rossi (2002) e também empregado neste artigo: o valor percebido é a aval iação geral pel o consumidor da utilidade de um produto baseada em percepções do que é recebido e do que é dado.

\section{Qualidade percebida do produto}

A qualidade percebida do produto compõe-se de atributos aos quais o cliente confere uma importância relativa, e que satisfazem necessidades ou expectativas (VALLE, 2003). Atributos são características pertinentes ao produto, no caso o imóvel, que são percebidos pelo comprador como geradores de benefícios, como o tipo da planta (aproveitamento inteligente da área total, por exemplo) ou a localização do apartamento (em rua tranqüila e segura, por exemplo). Leitão e Formoso (2000) constataram que os clientes anal isam o imóvel de maneira mais ampla, incluindo na sua percepção de satisfação com o produto, além do objeto físico, os serviços agregados.

A qualidade baseada numa diferença de preço é mais provável em uma situação em que o cliente esteja avaliando a informação na fase de decisão. N uma linguagem prescritiva, os vendedores precisariam, portanto, criar legitimidade na qualidade e no preço para os clientes em situações na qual a qualidade é difícil de ser avaliada antes da compra (URBANY e outros, 1997).

A qualidade percebida do produto aqui estudado é entendida de forma similar à apresentada na literatura em geral. Porém, percebeu-se, na fase exploratória da pesquisa (descrita mais adiante), que a qualidade percebida do produto apartamento na planta está ligada, na mai oria das vezes, a quatro atributos: (1) a qualidade da construção, percebida nas especificações dos acabamentos, conhecimento prévio de obras da mesma construtora, ou pelo acompanhamento da obra durante a construção; (2) a planta do apartamento, percebida pela sua praticidade ou por atender aos interesses do comprador; (3) a local ização, percebida por meio da proximidade do edifício em relação ao local de trabal ho, moradia de familiares, comércio, ou por se tratar do bairro em que o comprador mantém outros vínculos afetivos; e (4) pelos serviços oferecidos no edifício, como área de lazer e segurança. Assim, neste artigo, define-se a qualidade percebida do produto como sendo composta dos atributos acima, aos quais o cliente confere importância relativa, eque satisfazem suas necessidades e expectativas.

\section{DEFINIÇÃO DAS HIPÓTESES DA PESQUISA}

Com o objetivo de responder ao problema de pesquisa são testadas sete hipóteses que compõem o modelo teórico deste trabalho, apresentadas a seguir.

De acordo com Crosby e Stephens (1987), a satisfação geral do consumidor com um serviço possui três dimensões distintas, ou seja, satisfação com: (1) a pessoa com quem se fez o contato, neste caso o corretor; (2) o serviço principal, a qualidade e o valor percebido do produto, neste caso 0 apartamento na planta; e (3) a organização, neste caso a empresa incorporadora ou construtora.

A compra de um imóvel é normalmente planejada e está carregada de sentimentos como o estresse, o "sonho da casa própria" e outros tantos que fazem parte desse tipo de compra. Assim, a confiança é um construto importante no estudo apresentado, pois a percepção da confiança pelo cliente poderá afetar a satisfação com a compra do imóvel. Bigne e Blesa (2003) analisaram tanto o modelo da satisfação como antecedente da confiança quanto o modelo da confiança como antecedente da satisfação. Os autores aceitaram os dois model os, sendo que no modelo da confiança como antecedente da satisfação obtiveram índices mais significativos. Desse modo, concluíram que quanto maior a confiança, maior a satisfação. Daí, surge a primeira hipótese:

$\mathrm{H}_{1}$ : A confiança no corretor de imóveis percebida pel o cliente impacta positivamente a satisfação com a compra do imóvel na planta.

No entanto, a confiança no corretor de imóveis pode ser influenciada por outros construtos: (1) satisfação com o corretor de imóveis, (2) características do corretor de imóveis e (3) experiências anteriores e relacionamentos comerciais com corretores de imóveis em geral. 0 primeiro construto seria a satisfação com o nível do serviço e com o tipo de negociação, na percepção do cliente. No estudo de Ramsey e Sohi (1997), a confiança e a satisfação com o ven dedor foram importantes construtos em estágios iniciais de relacionamento, fundamentais para a constituição de relacionamentos duradouros. Já para o segundo construto, características do corretor, são considerados o perfil, 
o conhecimento ea credibilidade como fatores primordiais na construção da confiança (DONEY, CAN N ON , 1997). A integridade do vendedor também pode gerar confiança no comprador, como demonstrado por Ganesan (1994). 0 terceiro construto refere-se às experiências anteriores que o cliente teve com os corretores de imóveis. Doney e Cannon (1997) constataram que freqüentes contatos de negócios com os vendedores podem influenciar positivamente a confiança neles, e a freqüência de contatos pessoais das partes envolvidas na negociação tem forte influência na satisfação total (CROSBY, STEPPHENS, 1987). No presente artigo, as experiências pessoais com os corretores se baseiam nas percepções dos clientes em contatos anteriores por meio de compras ou locações precedentes de apartamentos, recomen dações de amigos, ou mesmo na procura prolongada da compra do imóvel em questão. Atributos dos corretores como conhecimento, experiência e nível de interesse podem influenciar a confiança percebida pelos clientes. Com isso, têm-se as hipóteses $\mathrm{H}_{2}, \mathrm{H}_{3}$ e $\mathrm{H}_{4}$ :

$\mathrm{H}_{2}$ : A satisfação com o corretor de imóveis afeta diretamente a confiança percebida pelo cliente no corretor de imóveis. $\mathrm{H}_{3}$ : As características do corretor de imóveis afetam positivamente a confiança percebida pelo cliente no corretor de imóveis.

$\mathrm{H}_{4}$ : As experiências anteriores e relacionamentos dos clientes com os corretores de imóveis afetam positivamente a confiança percebida pelo cliente no corretor de imóveis que vendeu o imóvel.

Tanto Crosby e outros (1990), como Bigne e Blesa (2003), concluíram que os construtos confiança e satisfação são positivamente relacionados. Bigne e Blesa (2003) constataram que comportamento de orientação de mercado do produtor tem efeito positivo na confiança do comprador e na satisfação com o relacionamento. Crosby e outros (1990) observaram que relacionamentos de qualidade dependem de confiança e satisfação, proporcionando antecipações de futuras intenções de compra. Neste artigo, a construção da confiança na construtora está associada não somente aos relacionamentos anteriores com a empresa, mas, principal mente, à sua credibilidade no mercado. Daí a quinta hipótese:

$\mathrm{H}_{5}$ : a confiança do cliente na construtora tem influência direta na satisfação com a compra do imóvel.

A avaliação do valor percebido do produto pelo cliente é comumente anal isada em relações de compras rotineiras e esporádicas, como no estudo de Sirdeshmukh e outros (2002), no qual o valor é percebido positivamente pela confiança nos empregados da linha defrente. Para Crosby e Stephens (1987), os compradores têm as informações que necessitam para avaliar o preço em relação ao valor do pacote total do serviços, inclusive dos serviços periféricos e do principal. Portanto, o valor percebido está associado não somente ao preço estipulado para venda, mas também ao esforço envolvido na aquisição do imóvel, e à percepção do benefício em relação ao valor pago. Assim, a sexta hipótese é:

$H_{6}$ : o valor percebido do produto pelo cliente tem influência direta na satisfação com a compra do imóvel.

U ma das dimensões positivas identificadas na satisfação por Bignee Blesa (2003) foi a do produto, que se referia à satisfação com a qualidade oferecida e a demanda. No presente artigo, verificou-se que existem dimensões diferentes na percepção da qualidade pelo comprador de um imóvel na planta. Foram diagnosticados, em fase qual itativa da pesquisa, outros atributos percebidos pel os clientes que influenciariam a escolha do imóvel e, conseqüentemente, a satisfação com tal escolha. A hipótese $\mathrm{H}_{7}$ é:

$\mathrm{H}_{7}$ : a qualidade percebida do produto pelo clientetem influência direta na satisfação com a compra do imóvel.

Baseado na literatura pesquisada, a partir dos estudos de Doney e Cannon (1997), Ganesan (1994) e Bigne e Blesa (2003), o modelo proposto para a pesquisa está apresentado na Figura 1, que ilustra as hipóteses a serem testadas.

\section{MÉTODO DE PESQUISA}

N esta seção, apresentam-se os procedimentos empregados para a operacionalização dos construtos, amostragem e coleta de observações, e análise dos dados.

\section{Operacionalização dos construtos}

Para medição das variáveis latentes, foram adaptadas escalas com base nas existentes na literatura. Elas foram escolhidas a partir das apresentadas por Bruner e Hensel (2001), de acordo com a que melhor se adequava à situação deste estudo. Todas as perguntas foram legitimadas por uma pesquisa qualitativa em um grupo piloto e pelo pré-teste do questionário final. O Quadro 1 apresenta um sumário dos indicadores das variáveis e suas escalas originais. 


\section{Procedimentos de amostragem e coleta de dados}

A população para a determinação da amostra consistiu em todas as pessoas que compraram apartamento na planta, no período de 2003 a 2005, na cidade de São Paulo, sendo difícil precisá-la pela falta de informações consolidadas sobre o setor. Partiu-se, então, para a coleta estruturada dos contatos de um banco de dados de 1.276 clientes de diversos empreendimentos de uma incorporadora e uma corretora de imóveis que atuam na cidade, para a composição da amostra, condicionada pela limitação da captação dos dados e pela disponibilidade da empresa em efetuar a pesquisa. Os dados primários foram obtidos nos meses de abril e maio de 2005, por meio de questionário estruturado contendo perguntas fechadas, aplicado por meio de entrevistas tel efônicas. Em conformidade com as recomen dações de Alreck e Settle (1995), o questionário foi organizado em duas grandes seções: a primeira com perguntas referentes às escal as de medição das variáveis, e a segunda com questões referentes à caracterização demográfica dos entrevistados. Foram usadas escalas de Likert com cinco categorias de respostas, que vão de "discordo totalmente" a "concordo totalmente"; e do tipo diferencial semântica (extremos associados a rótulos bipolares), também com cinco categorias. A taxa de aproveitamento de respostas foi de $25 \%$, o que gerou uma amostra com 270 respondentes.
Inicialmente foi escolhido, por conveniência, um grupo piloto de nove pessoas que compraram apartamento na planta na cidade do Rio de Janeiro esedispuseram a responder ao questionário. A pós a análise, os questionários foram refeitos e reenviados para o grupo piloto para nova crítica. Esse grupo, apesar de apresentar semelhanças com o perfil dos entrevistados da amostra, foi constituído de pessoas residentes eadquirentes deimóveis na cidade do Rio de Janeiro, não fazendo parte da amostra final da pesquisa.

$\mathrm{Na}$ seqüência, os questionários foram aplicados por atendentes da Central de Relacionamento da construtora/ incorporadora. Foi realizado um pré-teste com dez clientes selecionados da base de dados, que guardavam, assim, semelhanças com os entrevistados da pesquisa real em termos de familiaridade com o assunto e comportamentos de interesse. Todos os aspectos do questionário foram testados, inclusive o conteúdo das perguntas, os enunciados, a seqüência, as dificuldades, os entendimentos a respeito das questões, e as dúvidas não dimensionadas anteriormente. Após essa avaliação, um segundo questionário foi aplicado a uma nova amostra de dez clientes, não tendo sido necessária mais nenhuma alteração. 0 pré-teste foi feito, portanto, com 20 respondentes.

\section{Método de análise dos dados}

A análise dos dados foi feita com base no Modelo de

Figura 1 - Modelo proposto para a análise da relação entre os construtos

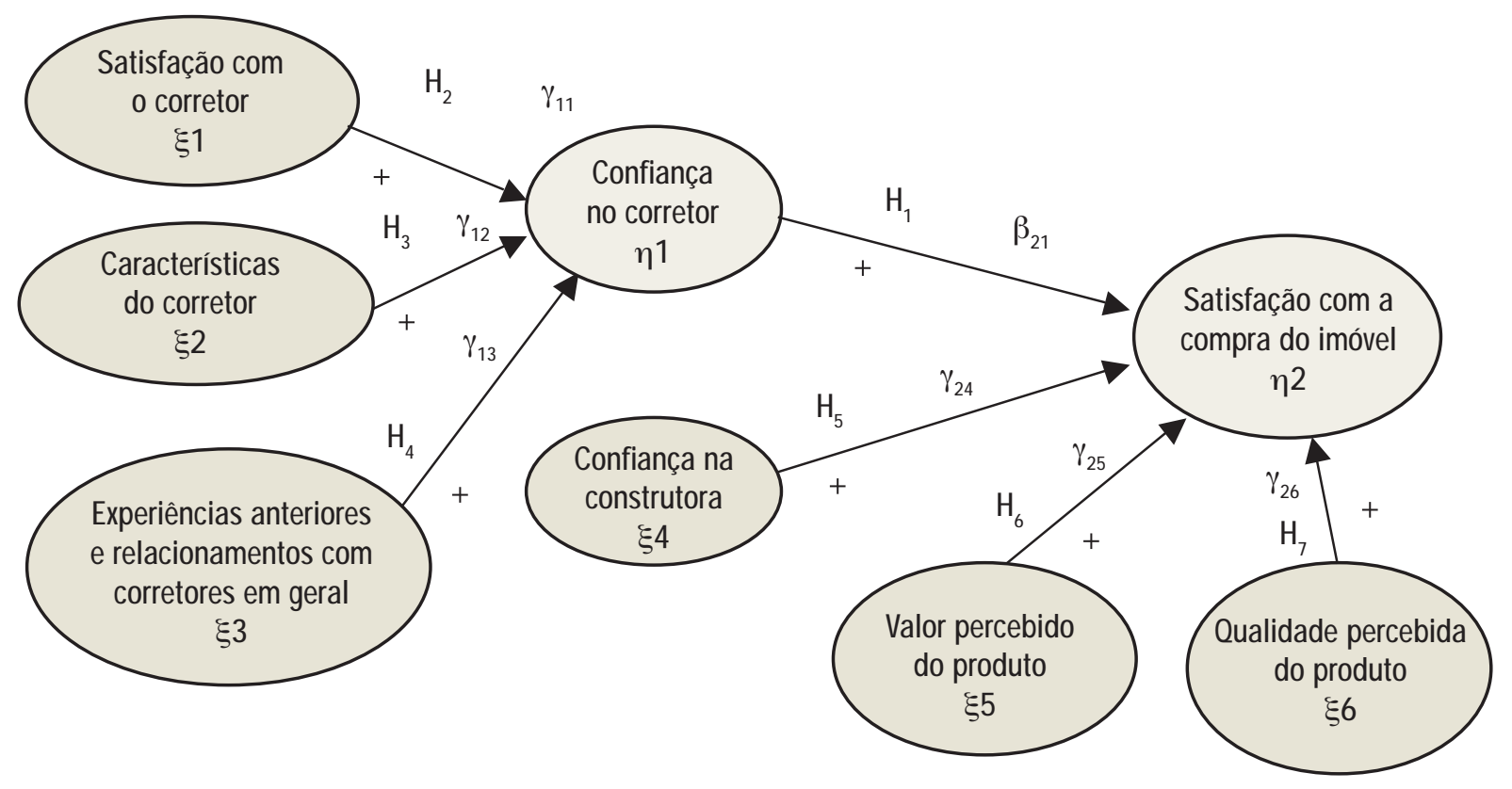


Equações Estruturais (SEM ), usando-se o software Lisrel 8. O SEM é uma metodologia estatística que assu me abordagem confirmatória para a análise multivariada de uma estrutura teórica (Byrne, 1998). Primeiramente, quando da geração da matriz de correlação policórica (PM ) no software Prelis, anal isou-se a normal idade dos dados. A análise gráfica mostrou que muitos indicadores apresentavam distribuição próxima da normal, mas outros nem tanto.

Quadro 1 - Indicadores das variáveis

\begin{tabular}{|c|c|c|}
\hline VARIÁVEIS DO MODELO & INDICADORES & ESCALA ORIGINAL \\
\hline \multirow{5}{*}{$\begin{array}{l}\text { Confiança no corretor } \\
\text { de imóveis }(\mathrm{Cc})-\eta_{1}\end{array}$} & Acessibilidade do corretor & \multirow{3}{*}{$\begin{array}{l}\text { Ramsey e Sohi (1997) - grau de } \\
\text { credibilidade }\end{array}$} \\
\hline & Sinceridade do corretor & \\
\hline & Risco envolvido na negociação & \\
\hline & Honestidade do corretor & Done e Cannon (1997) - credibilidade e preocupa- \\
\hline & Preocupação com os interesses dos clientes & ção com os interesses dos clientes (benevolência) \\
\hline \multirow{3}{*}{$\begin{array}{l}\text { Satisfação com o corretor } \\
\text { de imóveis (Sa) - } \xi\end{array}$} & Tranqüilidade na negociação & \multirow{3}{*}{$\begin{array}{l}\text { Ramsey e Sohi (1997) - grau de satisfação do cliente } \\
\text { com a experiência da interação com o vendedor }\end{array}$} \\
\hline & Nível do serviço prestado & \\
\hline & Satisfação com a negociação & \\
\hline \multirow{3}{*}{$\begin{array}{l}\text { Características do corretor } \\
\text { de imóveis (PF) - } \xi_{2}\end{array}$} & Amabilidade do corretor & \multirow{3}{*}{$\begin{array}{l}\text { Doney e Cannon (1997) - cordialidade, amabilidade } \\
\text { e similaridade do vendedor }\end{array}$} \\
\hline & Capacidade do corretor & \\
\hline & Similaridade do corretor & \\
\hline \multirow{3}{*}{$\begin{array}{l}\text { Experiências anteriores } \\
\text { e relacionamentos com } \\
\text { corretores em geral } \\
\text { (ER) }-\xi_{3}\end{array}$} & Acessibilidade do corretor & \multirow{3}{*}{$\begin{array}{l}\text { Doney e Cannon (1997) - habilidades dos vendedo- } \\
\text { res e dos freqüentes contatos com os clientes }\end{array}$} \\
\hline & Sinceridade do corretor & \\
\hline & Risco envolvido na negociação & \\
\hline \multirow{3}{*}{$\begin{array}{l}\text { Confiança na construtora } \\
\text { (CC) - } \xi_{5}\end{array}$} & Segurança, confiança na construtora & \multirow{3}{*}{$\begin{array}{l}\text { Andaleeb (1996) - confiança por meio da segurança } \\
\text { da sinceridade e do apoio do fabricante percebidos } \\
\text { pelo cliente }\end{array}$} \\
\hline & Sinceridade da construtora & \\
\hline & Apoio da construtora & \\
\hline \multirow{2}{*}{$\begin{array}{l}\text { Valor percebido do } \\
\text { produto (VP) - } \xi_{6}\end{array}$} & Preço pago & \multirow{2}{*}{$\begin{array}{l}\text { Sirdeshmukh e outros (2002) - valor percebido pelo } \\
\text { preço pago na compra e do esforço da compra }\end{array}$} \\
\hline & Esforço envolvido na compra & \\
\hline \multirow{4}{*}{$\begin{array}{l}\text { Qualidade percebida do } \\
\text { produto (QP) - } \xi_{7}\end{array}$} & Qualidade da construção & \multirow{2}{*}{$\begin{array}{l}\text { Urbany e outros (1997) - qualidade do apartamento } \\
\text { anunciado para locação }\end{array}$} \\
\hline & Qualidade da planta do apartamento & \\
\hline & Influência da localização do imóvel & \multirow{2}{*}{$\begin{array}{l}\text { A partir da qualidade percebida do produto pelo gru- } \\
\text { po piloto na fase qualitativa da pesquisa }\end{array}$} \\
\hline & Influência dos serviços oferecidos no edifício & \\
\hline \multirow{3}{*}{$\begin{array}{l}\text { Satisfação com a compra } \\
\text { do imóvel (Sal) - } \eta_{2}\end{array}$} & Satisfação da necessidade & \multirow{3}{*}{$\begin{array}{l}\text { Oliver (1999); Westbrook e Oliver (1991) - } \\
\text { satisfação com a compra }\end{array}$} \\
\hline & Satisfação com a decisão & \\
\hline & Satisfação com a escolha & \\
\hline
\end{tabular}


Posteriormente, os modelos - estrutural e de medidas foram estimados simultaneamente. A partir das recomendações de vários autores (JÖRESKOG, SÖRBOM, 1996; BYRNE, 1998; HAIR e outros, 1998; BOLLEN, 1989) para que os modelos obtenham boa validade, deve-se avaliar, basicamente: (a) se os indicadores de um mesmo construto têm índices satisfatórios de confiabilidade; (b) se as cargas fatoriais $\left(\lambda_{x}\right.$ e $\left.\lambda_{y}\right)$ em seus respectivos indicadores foram significantes; e (c) se o modelo de medidas se ajusta bem aos dados, ou seja, dentro de índices considerados satisfatórios. De acordo com Byrne (1998), os valores genericamente aceitos para os indicadores de ajustamento do modelo completo são: Raiz Quadrada da M édia do Erro de A proximação (RMSEA) entre 0,05 e 0,08, sendo zero a adequação perfeita; Raiz Quadrada M édia Residual (RM R) com valores inferiores a 0,05; Índice de Adequação do Ajuste (GFI) e Índice de Adequação Relativa (CFI) com valores próximos de 1 , sendo que maior do que 0,90 indica ótima adequação; e Índice de Adequação da Parcimônia Padrão (PNFI) acima de 0,50.

\section{ANÁLISE DOS RESULTADOS}

A Tabela 1 apresenta o perfil demográfico da amostra. A maioria dos respondentes $(96,3 \%)$ ainda não tinha recebido o imóvel quando respondeu ao questionário. 60,0\% da amostra tinham idade entre 26 e 35 anos e $57,4 \%$ eram solteiros; $62,6 \%$ apresentavam renda familiar entre R\$ $1.500,00$ e $R \$ 5.000,00$, e $58,5 \%$ cursaram pelo menos 0 curso superior.
Inicialmente, optou-se por examinar o ajustamento do modelo aos dados coletados pela anál ise das medidas de adequação. Os índices alcançados demonstraram que o model o inicial não se ajustou perfeitamente aos dados. Desse modo, diante da avaliação das estimativas, dos índices de modificação, dos val ores da estatísticat, e de acordo com as recomendações de Byrne (1998), o model o foi modificado na tentativa de se obter melhor ajustamento. Tal modificação se deu pela retirada de variáveis, não sendo acrescentado nenhum outro caminho entre as variáveis ou a ligação de indicadores com variáveis latentes diferentes do modelo original, visto que não havia justificativa teórica nem prática para tal. A pesar de terem sido anal isados os índices de modificação, não havia motivo para usá-los, não fazendo sentido as relações sugeridas. As comparações dos resultados obtidos em função das principais al terações testadas estão descritas na Tabela 2.

0 critério para a retirada das variáveis do modelo foram os baixos valores obtidos nas estimativas dos parâmetros e dos valores da estatística t de $\gamma_{26}(1,59), \gamma_{13}(0,65)$ e $\gamma 12$ $(0,16)$ no modelo inicial (considerando valores det maiores que 1,96, valor crítico ao nível de significância de 5\%) (BYRNE, 1998; BOLLEN, 1989; Jöreskog, Sörbom, 1996). Assim, foram retiradas do modelo três variáveis latentes exógenas: características do corretor, experiências anteriores com corretores em geral e qualidade percebida do produto. 0 model o com melhor ajustamento foi o modelo 4, chamado aqui de modelo final.

Foi reavaliada, ainda, a consistência interna de cada construto pelo alfa de Cronbach. Netemeyer e outros (2003) recomendam alfas com valores acima de 0,70,

Tabela 1 - Caracterização da amostra

\begin{tabular}{|c|c|c|c|c|c|}
\hline \multicolumn{2}{|c|}{ JÁ RECEBEU O IMÓVEL } & \multicolumn{2}{|l|}{ SEXO } & \multicolumn{2}{|l|}{ ESTADO CIVIL } \\
\hline Sim & $3,70 \%$ & Feminino & $42,22 \%$ & Solteiros & $57,41 \%$ \\
\hline \multirow[t]{3}{*}{ Não } & $96,30 \%$ & Masculino & $57,78 \%$ & Casados & $32,59 \%$ \\
\hline & & & & Divorciados & $6,30 \%$ \\
\hline & & & & Outros & $3,70 \%$ \\
\hline \multicolumn{2}{|c|}{ FAIXA DE IDADE } & \multicolumn{2}{|l|}{ RENDA FAMILIAR } & \multicolumn{2}{|l|}{ GRAU DE INSTRUÇÃO } \\
\hline até 25 & $12,59 \%$ & Menos de $R \$ 1.500,00$ & $0,74 \%$ & Colegial incompleto & $1,85 \%$ \\
\hline $26-35$ & $60,00 \%$ & $R \$ 1.500,00-R \$ 3.000,00$ & $32,22 \%$ & Colegial completo ou superior incompleto & $29,63 \%$ \\
\hline $36-45$ & $16,67 \%$ & $R \$ 3.001,00-R \$ 5.000,00$ & $30,37 \%$ & Superior completo & $58,52 \%$ \\
\hline $46-55$ & $4,44 \%$ & $R \$ 5.001,00-R \$ 10.000,00$ & $8,15 \%$ & Pós-graduação & $9,63 \%$ \\
\hline Mais de 55 & $5,93 \%$ & Mais de $\mathrm{R} \$ 10.000,00$ & $12,22 \%$ & Não respondeu & $0,37 \%$ \\
\hline Não responderam & $0,37 \%$ & Não responderam & $16,30 \%$ & & \\
\hline
\end{tabular}


principalmente quando existem mais de três indicadores medindo a variável. Em relação ao modelo inicial, os valores encontrados variaram de 0,51 a 0,87 , sendo que para as variáveis características do corretor de imóveis e satisfação com a compra do imóvel obtiveram-se valores de 0,51 e 0,53 respectivamente, e os demais acima de 0,73. Tais resultados corroboram a decisão da retirada dessas variáveis do modelo final.

Analisando-se separadamente os model os - de medidas e estrutural -, nota-se que os coeficientes de correlação múltipla dos indicadores são altos, demonstrando que a proporção da variância do indicador que é explicada pela sua variável latente é alta, sugerindo confiabilidade dos indicadores com valores acima de 0,50 (BYRNE, 1998). Os parâmetros do modelo de medidas foram significantes a 95\% de probabilidade. A Tabela 3 apresenta os valores das estatísticas t entre os indicadores e os construtos, para o model o final.

$\mathrm{Na}$ avaliação do modelo estrutural, objetiva-se determinar se as relações são suportadas pelos dados. Assim, consideram-se três aspectos: (1) os sinais dos parâmetros de $\gamma$ e $\beta$; (2) a magnitude e significância de $\gamma$ e $\beta$; e (3) os valores dos coeficientes de correlação para as equações estruturais (BYRNE, 1998). Verifica-se no modelo final que os $\gamma$ são positivos e significativos, assim como o $\beta$ e os coeficientes de correlação $(0,88$ e 0,57$)$. Em termos das relações propostas para as variáveis latentes, os resultados suportam as hipóteses $\mathrm{H}_{1}, \mathrm{H}_{2}, \mathrm{H}_{5} \mathrm{e}$ $\mathrm{H}_{6,}$ e rejeitam as hipóteses $\mathrm{H}_{3}, \mathrm{H}_{4}$ e $\mathrm{H}_{7}$, conforme apresentado na Tabela 4.

N ota-se, na Tabela 2, sensível melhora deal gunsíndices de ajustamento no model o final, indicando que as modificações efetuadas foram adequadas. A diferença do quiquadrado encontrada entre o model o inicial e o final é de $1.018,86$. Os valores de RMSEA indicam boa adequação, em contraste com os valores obtidos para RM R, acima do esperado. Já o ECVI do modelo final é significativamente melhor que o inicial, levando a crer que há mais possibilidade de o modelo final ser validado em outras amostras da mesma população. Tanto os índices encontrados para GFI quanto para CFI no model o final estão mais próximos de 1, indicando melhor adequação em relação ao modeIo inicial. Os índices de PNFI estão acima do esperado, mas podem ter sido sensíveis ao tamanho da amostra e à normalidade dos dados (BYRNE, 1998). 0 modelo final é apresentado na Figura 2.

Tabela 2 - Comparação dos resultados dos modelos testados

\begin{tabular}{|c|c|c|c|c|c|c|c|c|c|c|}
\hline $\begin{array}{l}0 \\
\text { 吕 } \\
8 \\
\Sigma\end{array}$ & 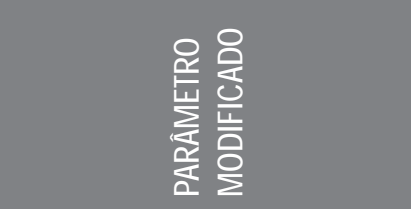 & ${ }^{n} x$ & $\begin{array}{l}8 \\
8 \\
\frac{8}{4} \\
\frac{1}{5} \\
3\end{array}$ & 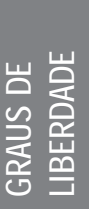 & $\sum_{\substack{\mathbb{1} \\
\mathbb{W}}}^{\mathbb{W}}$ & $\underset{\amalg}{J}$ & $\begin{array}{l}\frac{1}{14} \\
\frac{1}{1} \\
\frac{1}{\alpha} \\
\frac{\alpha}{3}\end{array}$ & $\mathbb{6}$ & $\frac{5}{2}$ & $\overline{8}$ \\
\hline $\begin{array}{c}1 \\
\text { Inicial }\end{array}$ & & $1.901,50$ & & 287 & 0,00 & 5,42 & 0,17 & 0,72 & 0,62 & 0,74 \\
\hline 2 & $\begin{array}{l}\text { Sem a variável qualidade per- } \\
\text { cebida - retirada de } \gamma_{26}\end{array}$ & $1.485,33$ & 416,17 & 200 & 0,00 & 4,35 & 0,17 & 0,74 & 0,65 & 0,77 \\
\hline 3 & $\begin{array}{l}\text { Sem duas variáveis - retirados } \\
\gamma_{26} \text { e } \gamma_{13}\end{array}$ & $1.184,50$ & 300,83 & 145 & 0,00 & 3,48 & 0,17 & 0,75 & 0,65 & 0,78 \\
\hline $\begin{array}{c}4 \\
\text { Final }\end{array}$ & $\begin{array}{l}\text { Sem três variáveis - retirados } \\
\gamma_{26}, \gamma_{13} \text { e } \gamma_{12}\end{array}$ & 882,64 & 301,86 & 99 & 0,00 & 2,35 & 0,18 & 0,79 & 0,65 & 0,81 \\
\hline
\end{tabular}

Nota: RMSEA - Raiz Quadrada Média do Erro de Aproximação; ECVI - Índice Esperado de Validação Cruzada; RMR - Raiz Quadrada M édia Residual; GFI - Índice de Boa Adequação; PNFI - Índice de Adequação da Parcimônia Padrão; CFI - Índice de Adequação Comparativo. 


\section{CONSIDERAÇÕES FINAIS}

O foco desta pesquisa foi propor um model o de confiança esatisfação aplicado ao setor imobiliário, diagnosticandose, com isso, que a confiança está presente não só nos relacionamentos de longo prazo entre clientes e vendedores ou organizações, mas também na primeira compra quando esta representa um al to envolvimento para o cliente, como a compra de um imóvel.

Diante dos resultados obtidos, a não rejeição das hipóteses $\mathrm{H}_{1}, \mathrm{H}_{2}, \mathrm{H}_{5}$ e $\mathrm{H}_{6}$ leva à conclusão de que, na amostra analisada, a confiança no corretor, assim como a confiança na construtora e o valor percebido do produto, são ante- cedentes da satisfação com a compra do imóvel na planta, assim como o é a satisfação com o corretor, medida pela confiança nele. N uma análise comparativa das dimensões de cada efeito, nota-se que a maior influência foi a variável satisfação com o corretor sobre a variável confiança no corretor $\left(\gamma_{11}=0,98\right)$, o que pode implicar aos gestores de marketing imobiliário que a tranqüilidade na negociação e o nível do serviço prestado pelo corretor deveriam ser enfatizados num treinamento de vendas, para que a confiança do cliente no corretor seja incrementada. A confiança, um construto importante no marketing de relacionamento, sinaliza ser uma variável relevante na satisfação com a compra de imóveis.

Tabela 3 - Estatísticas t do modelo de medidas do modelo final

\begin{tabular}{|c|c|c|c|c|c|}
\hline & $\begin{array}{l}\text { CONFIANÇA NO } \\
\text { CORRETOR }\end{array}$ & $\begin{array}{c}\text { SATSFAÇÃO COM A } \\
\text { COMPRA }\end{array}$ & $\begin{array}{l}\text { SATISFACCÃO COM O } \\
\text { CORRETOR }\end{array}$ & $\begin{array}{l}\text { CONFIANÇA NA } \\
\text { CONSTRUTORA }\end{array}$ & $\begin{array}{c}\text { VALOR PERCEBIDO DO } \\
\text { PRODUTO }\end{array}$ \\
\hline$C c 2^{\mathrm{a}}$ & $(18,11)$ & & & & \\
\hline $\mathrm{Cc} 3$ & $(9,90)$ & & & & \\
\hline $\mathrm{Cc} 4$ & $(17,93)$ & & & & \\
\hline Cc5 & $(14,16)$ & & & & \\
\hline Sal2 & & $(12,24)$ & & & \\
\hline Sal3 & & $(12,18)$ & & & \\
\hline Sa2 & & & $(18,79)$ & & \\
\hline Sa3 & & & $(18,76)$ & & \\
\hline $\mathrm{CC} 2$ & & & & $(17,80)$ & \\
\hline CC3 & & & & $(18,12)$ & \\
\hline VP2 & & & & & $(9,56)$ \\
\hline
\end{tabular}

a Para os indicadores Cc1, Sal1, Sa1,CC1 e VP1 foi atribuído o valor de 1 para as cargas fatoriais, fixando-se as escalas das medidas, sendo uma condição suficiente como regra de identificação do modelo (JÖRESKOG, SÖRBOM, 1996).

Tabela 4 - Análise das hipóteses testadas na pesquisa

\begin{tabular}{|l|l|c|l|}
\hline & \multicolumn{1}{|c|}{ HIPÓTESE } & VALORES & \multicolumn{1}{c|}{ RESULTADO } \\
\hline $\mathrm{H}_{1}$ & Confiança no corretor impacta positivamente a satisfação com a compra & $+\mathbf{6 , 6 6}$ & Não rejeitada \\
\hline $\mathrm{H}_{2}$ & Satisfação com o corretor afeta positivamente a confiança nele(a) & $\mathbf{+ 1 4 , 1 8}$ & Não rejeitada \\
\hline $\mathrm{H}_{3}$ & Características do corretor afetam positivamente a confiança nele(a) & $+0,16$ & Rejeitada \\
\hline $\mathrm{H}_{4}$ & Experiências anteriores afetam positivamente a confiança no corretor & $+0,65$ & Rejeitada \\
\hline $\mathrm{H}_{5}$ & Confiança na construtora influencia positivamente a satisfação com a compra & $+\mathbf{4 , 4 2}$ & Não rejeitada \\
\hline $\mathrm{H}_{6}$ & Valor percebido impacta positivamente a satisfação com a compra & $+\mathbf{6 , 6 8}$ & Não rejeitada \\
\hline $\mathrm{H}_{7}$ & Qualidade percebida do produto afeta positivamente a satisfação com a compra & $+1,59$ & Rejeitada \\
\hline
\end{tabular}


Apesar de não terem sido considerados os benefícios do produto na medição de seu valor percebido, mas apenas seus custos monetários e não monetários (val or percebido pelo preço pago na compra e esforço de compra, respectivamente) , o fato de essa variável apresentar efeito significante como antecedente da satisfação $\left(\gamma_{25}=0,41\right)$ indica que tais custos não deveriam ser desprezados em análises desse mercado. Um custo não monetário relevante para o comprador de um bem (ainda intangível) de tão al to valor inclui o estresse da compra, principalmente devido ao risco de uma compra malfeita. Garantias de entrega e de qualidade, além de políticas de devolução de dinheiro, podem ser el aboradas pel os profissionais do setor para a redução de tal estresse, como ocorre em al guns setores de bens de consumo, como roupas e eletrônicos. 0 efeito da variável confiança na construtora sobre a satisfação com a compra $\left(\gamma_{24}=0,19\right)$ foi o menor dos efeitos significantes dentre as relações entre as variáveis testadas, mas ainda assim indica a importância de a construtora desenvolver confiança junto ao mercado, por meio de desenvolvimento de marca, entrega no prazo, estimulação de notícias positivas na mídia, cumprimento de normas técnicas, entre outros, já que desconfianças em relação à capacidade de entrega do imóvel por parte da empresa podem povoar a mente do consumidor na compra de um imóvel na planta.

Com a rejeição das hipóteses $\mathrm{H}_{3}$ e $\mathrm{H}_{4}$, diagnosticou-se queas características do corretor de imóveis, experiências anteriores e relacionamentos do cliente com os corretores em geral, conforme operacionalizados neste artigo, não influenciam a confiança com tais corretores. Os resultados são similares aos constatados por Doney e Cannon (1997), pois al gumas dimensões de características do vendedor, como habilidade, e de experiências anteriores e relacionamentos, como interações sociais entre o comprador e o vendedor, não se relacionaram com a confiança. Ademais, recomendações desses autores enfatizam que a avaliação do processo de construção da confiança pode ser mais bem aplicada aos vendedores como representantes das empresas. Futuras pesquisas poderiam incluir a variável práticas gerenciais da imobiliária como antecedente da confiança no corretor para elucidar essa questão.

A rejeição de $\mathrm{H}_{7}$ indica que a qualidade percebida do produto não influencia a satisfação com a compra. Isso pode ter sido influenciado pelo fato de que a maioria dos entrevistados (96,3\%) ainda não tinha recebido o imóvel na época do levantamento de campo. Porém, na pesquisa qualitativa, os entrevistados informaram que suas escoIhas também se basearam, quando da compra do imóvel, em itens específicos oferecidos. Assim, compradores com filhos pequenos procuravam, normal mente, imóveis com itens como piscina e playground, localizados perto do local de trabal ho ou de familiares que pudessem ajudar na administração do dia-a-dia, além de itens de segurança. 0 tamanho da família é outro fator que determinaria a quantidade mínima de quartos e dos espaços. Desse modo, há uma percepção da qualidade do produto imóvel na planta, mesmo que o produto ainda não esteja tangível.

Figura 2 - Modelo final da pesquisa

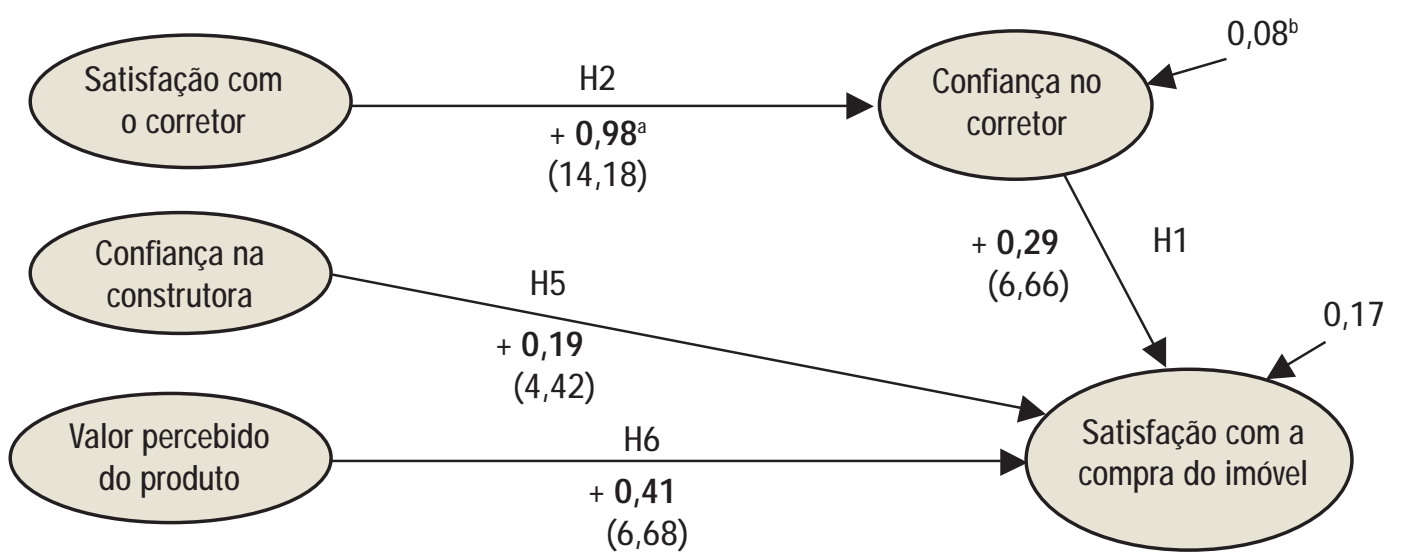

a Valores das estimativas. Estatísticas t entre parênteses.

b Valores de $\zeta$ (Zeta). 
Pesquisas futuras poderiam tratar do desenvolvimento e da validação de escal as métricas específicas para a percepção de qualidade de produtos de natureza tão particular como um imóvel na planta.

Para os tomadores de decisões das empresas construtoras, incorporadoras, imobiliárias, ou mesmo empresas que ofertam produtos de al to valor, como viagens de longa duração ou festas de casamento, em que há um grande envolvimento do cliente e que o produto ainda não se tornou tangível na perspectiva do comprador, há possibilidades de pesquisas aproveitando-se as variáveis aqui testadas e suas relações.

Esta pesquisa apresenta limitações, como sua amostra por conveniência, que contém dados obtidos somente em duas empresas de uma única cidade brasileira. Outra limitação foi a operacionalização da variável valor percebido, que se baseou apenas na perspectivas de custos, não incluindo benefícios (este foram incluídos em outra variável: qualidade percebida). Futuros trabalhos devem considerar tais limitações. Os pesquisadores podem conduzir levantamentos com clientes que não compraram 0 imóvel após a visita ao estande de vendas ou, ainda, com compradores de imóveis prontos.

Pesquisas comparativas do modelo final aqui obtido com outras amostras podem ajudar a compreender o fenômeno da satisfação no mercado imobiliário, como também estudos comparativos em cidades e regiões diferentes, visto que variáveis importantes na decisão de escolha de imóveis na planta, como índice de violência, congestionamento de vias públicas, marca da construtora e aspectos culturais, que influenciam o gosto do comprador, variam de uma cidade ou região para outra.

\section{REFERÊNCIAS}

ANDALEEB, S. S. An experimental investigation of satisfaction and commitment in marketing channels: the role of trust and dependence. Journal of Retailing, v. 72, n. 1, p. 77-93, 1996.

ALRECK, P.; SETTLE, R. B. The survey research handbook - guidelines and strategies for conducting a survey. 2nd Ed. New York: McGraw-Hill, 1995.

BIGNE, E.; BLESA, A. Market orientation, trust and satisfaction in dyadic relationships: a manufacturer-retailer analysis. International Journal of Retail e Distribution Management, v. 31, n. 11, p. 574-590, 2003.

BERRY, L. L.; PARASURAMAN , A. Serviços de marketing: competindo através da qualidade. $3^{\text {a }}$ ed. São Paulo: Maltese, 1995.

BOLLEN, D. A. Structural equations with latent variables. N ew York: John Wiley \& Sons Inc., 1989.
BOTELHO, D. Consumer behavior on the internet: trust and perception of security control in the Brazilian context. AM A Winter Educators' Conference Proceedings, v. 18, p. 177-187, 2007.

BRETZKE, M. Comportamento do cliente. In: DIAS, S. R. (Org). Gestão de marketing. São Paulo: Saraiva, 2003.

BREI, V. A.; ROSSI, C. A. V. Confiança, valor percebido e lealdade em trocas relacionais de serviços: um estudo com usuários de internet banking no Brasil. In: ENCONTRO DA ASSO CIAÇÃO NACIONAL DOSPROGRAMAS DE PÓS-GRADUAÇÃO EM ADMINISTRAÇÃO 26‥2002, Salvador. Anais[...] Salvador: AN PAD, 2002.

BRUNER, G. C.; HENSEL, P. J. M arketing scales handbook: compilation of multi-item measures. V. 3. Chicago: American Marketing Association, 2001.

BYRNE, B. M. Structural equation modeling with Lisrel, Prelis, and Simplis: basic concepts, applications, and programming. Mahwah, NJ: Lawrence Erlbaum, 1998.

CHAUVEL, M. A. Consumidores insatisfeitos: uma oportunidade para as empresas. Rio de Janeiro: Mauad, 2000.

CHUNG, J. E.; STERN QUIST, B., CHEN , Z. Japanese retail-buyer-supplier relationships: does performance matter? Asia Pacific Journal of $M$ arketing and Logistics, v. 20, n. 1, p.55-75, 2008.

CROSBY, L. A.; EVANS, K. R.; COWLES, D. Relationship quality in services selling: an interpersonal influence perspective. Journal of M arketing, v. 25, n. 2, p. 127-137, 1990.

CROSBY, L. A.; STEPHENS, N. Effects of relationship marketing on satisfaction, retention, and prices in the life insurance industry. Journal of Marketing Research, v. 24, n. 4, p. 404-411, 1987.

DONEY, P. M.; CAN NON, J. P. An examination of nature of trust in buyerseller relationships. Journal of M arketing, v. 61, n. 2, p. 35-52, 1997.

FLAVIÁN, C.; GUINALÍU, M.; GURREA, R. The role played by perceived usability, satisfaction and consumer trust on website loyalty. Information \& Management, v. 43, n. 1, p. 1-14, 2006.

GANESAN, S. Determinants of long-term orientation in buyer-seller relationships. Journal of Marketing, v. 58, n. 2, p. 1-19, 1994.

GARBARINO, E.; JOHNSON, M. The different roles of satisfaction, trust and commitment for relational and transactional consumers. Journal of Marketing, v. 63, n. 2, p. 70-87, 1999.

HAIR JR., J. F.; ANDERSON, R. E.; TATHAM, R. L.; BLACK, W. C. Multivariate data analysis. 5th Ed. Upper Saddle River, NJ: Prentice Hall, 1998.

JÖRESKOG, K. G.; SÖRBOM, D. Lisrel 8: user's reference guide. Illinois: SSI, 1996.

LEITÃO, E. S.; FORMOSO, C. T. Análise do comportamento de compra de imóveis residenciais - estudo de caso: apartamentos novos de dois e três dormitórios. In: ENCONTRO NACIONAL DE TECNOLOGIA DO AMBIENTE CONSTRUÍDO, 8‥ 2000, Salvador. Anais[...] Salvador: Antac, 2000. 
MORGAN, R. M.; HUNT, S. D. The commitment-trust theory of relationship marketing. Journal of M arketing, v. 58, n. 3, p. 20-38, 1994.

MÜCKENBERGER, E. O papel da satisfação, confiança e comprometimento na formação de intenções futuras de compra entre clientes com níveis de experiência diferenciados. In: ENCONTRO DA ASSOCIAÇÃO NACIONAL DOS PROGRAMAS DE PÓS-GRADUAÇÃO EM ADMINISTRAÇÃO, 25․ 2001, Campinas. Anais[...] Campinas: AN PAD, 2001.

MUTRAN, A. Construtoras têm adotado modernas técnicas de relacionamento para aumentar a confiança de seus clientes e gerar mais vendas. Revista Construção, p. 32-37, 2003.

NEDER, V. Imóvel na planta: administradora ou incorporadora? Jornal do Comércio. Rio de Janeiro, 20.06.2004. Caderno Casa Própria, p. 1.

NetemeYER, R. G.; BEARDEN, W. O.; SHARMA, S. Scaling Procedures: Issues and Applications. Thousand Oaks: Sage, 2003.

OLIVER, R. L. Whence consumer loyalty? Journal of Marketing, v. $63, n$. 4, p. 33-44, 1999.

RAMSEY, R. P.; SOHI, R. S. Listening to your customers: the impact of perceived salesperson listening behavior on relationship outcomes. Journal of the Academy of M arketing Science, v. 25, n. 2, p. 127-137, 1997.

ROCHA, A.; CHRISTENSEN, C. M arketing: teoria e prática no Brasil. 1a Ed. São Paulo: Atlas, 1987.

SANTOS, C. P. Construção e teste de um modelo teórico sobre o impacto do gerenciamento de reclamações na confiança e lealdade do consumidor, no contexto de trocas de serviços relacionais. In: ENCONTRO DA ASSOCIAÇÃO NACIONAL DOS PROGRAMAS DE PÓS-GRADUAÇÃO EM ADMINISTRAÇÃO, 25․ 2001, Campinas. Anais[...] Campinas: AN PAD, 2001.

SANTOS, C. P.; ROSSI, C. A. V. Os antecedentes da confiança do consumidor em episódios envolvendo reclamações sobre serviços. In: ENCONTRO
DA ASSO CIAÇÃO NACIONAL DOSPROGRAMASDE PÓS-GRADUAÇÃO EM ADMINISTRAÇÃO, 26‥ 2002, Salvador. Anais[...] Salvador: AN PAD, 2002.

SANTOS, C. P.; FERNANDES, D. H. A recuperação de serviços e seu efeito na confiança e lealdade do cliente. In: ENCONTRO DE MARKETING DA AN PAD, 1‥ 2004, Porto Alegre. Anais[...] Porto Alegre: EMA, 2004.

SANTOS, C. P.; FERNANDES, D. H. A recuperação de serviços como ferramenta de relacionamento e seu impacto na confiança e leal dade dos clientes. Revista de Administração de Empresas, v. 48, n. 1, p. 10-24, 2008.

SIRDESHMUKH, D.; SINGH, J.; SABOL, B. Consumer trust, value, and loyalty in relational exchanges. Journal of Marketing, v. 66, n. 1, p. 15-37, 2002.

SUH, B.; HAN, I. The impact of customer trust and perception of security control on the acceptance of electronic commerce. International Journal of Electronic Commerce, v. 7, n. 3, p. 135-161, 2003.

SWAN, J. E.; TRAWICK, F. I.; SILVA JR., D. W. How industrial salespeople gain customer trust. Industrial Marketing Management, v. 14, n. 3, p. 203-211, 1985.

URBANY, J. E.; BEARDEN, W. O.; KAICKER, A.; BORRERO, M. S. Transaction utility effects when quality is uncertain. Journal of the Academy of Marketing Science, v. 25, n. 1, p. 45-55, 1997.

VALLE, A. L. Palavras e expressões do mercado imobiliário. São Paulo: Indusplan, 2003

WESTBRO OK, R. A.; OLIVER, R. L. The dimensionality of consumption emotion patterns and consumers satisfaction. Journal of Consumer Research, v. 18, n. 1, p. 84-91, 1991.

ZEITHAML, V. A. Consumer perceptions of price, quality, and value: a means-end model and synthesis of evidence. Journal of Marketing, v. 52, n. 3, p. 2-22, 1988.

\section{Artigo recebido em 13.05.2005. A provado em 07.03.2008.}

\section{Alda Rosana Duarte de Almeida}

Doutoranda em Administração (Marketing) pela Faculdade de Economia Administração e Contabilidade, Universidade de São Paulo

Interesses de pesquisa nas áreas de comportamento do consumidor, emoções do consumidor e marketing quantitativo

E-mail: aldarosana@globo.com

Endereço: Av. Prof. Luciano Gual berto, 908, Cidade Universitária, São Paulo - SP, 05508-010

\section{Delane Botelho}

Professor da Escola Brasileira de Administração Pública e de Empresas, Fundação Getulio Vargas

Doutor em Administração pela Escola de Administração de Empresas de São Paulo, Fundação Getulio Vargas

Interesses de pesquisa nas áreas de marketing quantitativo e na interface entre marketing e políticas públicas

E-mail: delane.botelho@fgv.br

Endereço: Praia de Botafogo, 190-506, Rio de Janeiro - RJ, 22250-900 